\title{
Ultrasound-Mediated One-Pot Synthesis of 7-Methyl-Substituted Pyrido[4,3-d]pyrimidine Scaffolds by a Catalyst-Free Protocol
}

\section{Manas M. Sarmah \\ Dipak Prajapati*}

Medicinal Chemistry Division, CSIR-North-East Institute of Science \& Technology, Jorhat - 785006, Assam, India

dr_dprajapati2003@yahoo.co.uk
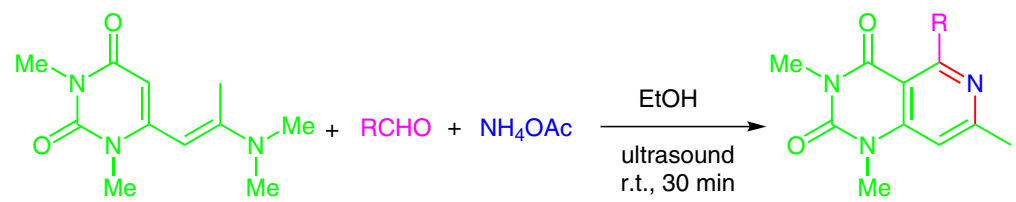

Received: 18.08.2014

Accepted after revision: 12.10.2014

Published online: 11.11 .2014

DOI: 10.1055/s-0034-1378923; Art ID: st-2014-d0693-

Abstract A one-pot and catalyst-free protocol for the construction of 7-methyl-substituted pyrido[4,3-d]pyrimidine derivatives from ethanolic solution of 6-[2-(dimethylamino)prop-1-enyl]-1,3-dimethyluracil, aromatic aldehyde, and ammonium acetate is described under both ultrasound and thermal conditions. The ultrasound methodology is clean and the desired products are obtained with good yields in short time.

Key words multicomponent reactions, aza-Diels-Alder, one-pot, pyrido[4,3-d]pyrimidine, ultrasound-assisted organic synthesis, green chemistry

Ultrasound-assisted organic synthesis (UAOS) has attracted considerable interest in terms of selectivity, reaction time, catalyst recyclability, and operational simplicity; ${ }^{1}$ features that make UAOS an interesting alternative technique to synthesize structurally diverse organic compounds. $^{2}$

Recently, our group synthesized a number of pyrimidine-containing scaffolds using the concept of a one-pot, multicomponent aza-Diels-Alder reaction strategy. ${ }^{3}$ On the basis of literature reports on 6-[2-(dimethylamino)vinyl]1,3-dimethyluracil (1a, Figure 1), ${ }^{3 \mathrm{~b}-\mathrm{e}}$ we turned our attention to explore the diene nature of the acetamidine modification of 1a, that is, 6-[2-(dimethylamino)prop-1-enyl]1,3-dimethyluracil (1) b). Almost two decades ago, Tsupak's group ${ }^{4}$ established a method to synthesize pyrrolo[3,2d]pyrimidines from 5-nitro-substituted 6-[2-(dimethylamino)prop-1-enyl]-1,3-dimethyluracil (1c), but the chemistry of 6-[2-(dimethylamino)prop-1-enyl]-1,3-dimethyluracil has received little attention. In an extension of our work on uracil systems, we demonstrate in this communication an ultrasound-mediated and catalyst-free three-component procedure, reacting 6-[2-(dimethylamino)prop-1-enyl]1,3-dimethyluracil with aromatic aldehydes and ammonium acetate for the generation of various 7-methyl-substituted pyrido[4,3- $d$ ]pyrimidine templates. Although preparations of 7-aryl-substituted pyrido[4,3-d]pyrimi- dines and their salts have been previously reported, ${ }^{5}$ to the best of our knowledge this is the first report of the synthesis of 7-methyl-substituted pyrido[4,3- $d$ ]pyrimidine derivatives using 6-[2-(dimethylamino)prop-1-enyl]-1,3-dimethyluracil as one of the starting materials under ultrasonication. In addition this ultrasound-mediated catalystfree methodology for the preparation of 7-methyl-substituted pyrido[4,3- $d]$ pyrimidines avoids forcing reaction conditions.<smiles>CN(C)/C=C/c1cc(=O)n(C)c(=O)n1C</smiles><smiles>C/C(=C\c1cc(=O)n(C)c(=O)n1N(C)C)N(C)O</smiles><smiles>C/C(=C\c1c([N+](=O)[O-])c(=O)n(C)c(=O)n1N(C)C)N(C)C</smiles>

Figure 1

In an earlier report we published a method for the synthesis of pyrido[4,3- $d$ ]pyrimidines wherein we applied a microwave-promoted, multicomponent aza-Diels-Alder strategy to achieve our goal. ${ }^{3 e}$ However, the repetition of the same methodology with a mixture of 6-[2-(dimethylamino)prop-1-enyl]-1,3-dimethyluracil (1b, $1 \mathrm{mmol})$, 4fluorobenzaldehyde (2a, $1 \mathrm{mmol})$, and urea $(2 \mathrm{mmol}$ ) only led to decomposition of the starting materials. This observation forced us to modify conditions by replacement of the urea with ammonium acetate (3a, $2 \mathrm{mmol}$ ) and use of a solvent leading to formation of the product in poor yield accompanied by byproducts. We then applied ultrasound and found progress of the reaction when an ethanolic solution of the reaction mixture was ultrasonicated, leading to the formation of 5-(4-fluorophenyl)-1,3,7-trimethylpyrido[4,3- 
d]pyrimidine-2,4-dione (4a) in $85 \%$ yield (Scheme 1 ). The reaction failed when carried out in the absence of solvent or in water.<smiles>CCOC(C)(C)C(=O)OCc1cc(=O)n(C)c(=O)n1C</smiles>
$2 a$

3a

Scheme 1

Using these optimized conditions, the viability of the reaction scheme was then tested with a range of aromatic aldehydes 2 , and the results obtained are shown in Table 1 and Scheme $2{ }^{6}$

Optimization studies showed that the reaction conditions are tolerated by a range of different aromatic aldehydes containing either electron-donating or electronwithdrawing substituents on the aromatic ring (Table 1, entries 1-13), with aromatic aldehydes possessing an electron-withdrawing group gave higher yields than aromatic aldehydes with electron-donating groups (Table 1, entries 1 and 8). It is noteworthy that para-substituted aldehydes gave better yields than meta-substituted aldehydes (Table 1 , entries 2, 3 and 5,6) and these, in turn, gave better yields than their ortho-substituted counterparts (Table 1, entries $3,4$ and 6,7$)$. The reaction was successful with heteroaromatic aldehydes such as thiophen-2-carbaldehyde and furfuraldehyde (Table 1, entries 12 and 13). Unfortunately, the reaction was unsuccessful with aliphatic aldehydes despite applying long reaction times. Aromatic aldehydes such as phenyl glyoxal and its derivatives were also unreactive under the optimized conditions. The regioselectivity obtained during the formation of 7-methyl-substituted pyrido[4,3$d$ ]pyrimidine derivatives is fully consistent with the electron-donating effect of the methyl-substituted aminovinyl moiety which increases the nucleophilicity of the C-5 position. Trace amounts of aldehyde and 6-[2-(dimethylamino)prop-1-enyl]-1,3-dimethyluracil remained in every case and these were removed by column chromatography. All of the products obtained were characterized spectroscopically.

Table 1 Direct Synthesis of a Library of 7-Methyl-Substituted Pyrido[4,3-d]pyrimidines $\mathbf{4 a -} \mathbf{m}^{\mathrm{a}}$

\begin{tabular}{lllll}
\hline Entry & $\mathrm{R}$ & Product & Reaction conditions & Yield (\%) \\
\hline 1 & $4-\mathrm{FC}_{6} \mathrm{H}_{4}$ & $\mathbf{4 a}$ & US/reflux & $85 / 75$ \\
2 & $4-\mathrm{BrC}_{6} \mathrm{H}_{4}$ & $\mathbf{4 b}$ & US/reflux & $85 / 74$ \\
3 & $3-\mathrm{BrC}_{6} \mathrm{H}_{4}$ & $\mathbf{4 c}$ & US/reflux & $83 / 72$ \\
4 & $2-\mathrm{BrC}_{6} \mathrm{H}_{4}$ & $\mathbf{4 d}$ & US/reflux & $80 / 69$ \\
5 & $4-\mathrm{ClC}_{6} \mathrm{H}_{4}$ & $\mathbf{4 e}$ & US/reflux & $84 / 75$ \\
6 & $3-\mathrm{ClC}_{6} \mathrm{H}_{4}$ & $\mathbf{4 f}$ & US/reflux & $81 / 70$ \\
7 & $2-\mathrm{ClC}_{6} \mathrm{H}_{4}$ & $\mathbf{4 g}$ & US/reflux & $78 / 65$ \\
8 & $4-\mathrm{MeC}_{6} \mathrm{H}_{4}$ & $\mathbf{4 h}$ & US/reflux & $83 / 73$ \\
9 & $3-\mathrm{MeC}_{6} \mathrm{H}$ & $\mathbf{4 i}$ & US/reflux & $82 / 72$ \\
10 & $2-\mathrm{MeC}_{6} \mathrm{H}_{4}$ & $\mathbf{4 j}$ & US/reflux & $77 / 65$ \\
11 & $4-\mathrm{MeOC}_{6} \mathrm{H}_{4}$ & $\mathbf{4 k}$ & US/reflux & $83 / 71$ \\
12 & $\mathrm{C}_{4} \mathrm{H}_{3} \mathrm{~S}$ & $\mathbf{4 l}$ & US/reflux & $80 / 71$ \\
13 & $\mathrm{C}_{4} \mathrm{H}_{3} \mathrm{O}$ & $\mathbf{4 m}$ & US/reflux & $79 / 75$ \\
\hline
\end{tabular}

a Reaction conditions: (i) 6-[2-(dimethylamino)prop-1-enyl]-1,3-dimethyluracil (1b, $1 \mathrm{mmol})$, aromatic aldehyde (2,1 mmol), $\mathrm{NH}_{4} \mathrm{OAc}$ (3a, $\left.2 \mathrm{mmol}\right)$, EtOH (5 mL), ultrasound at 70\% amplitude, 30 min; (ii) 6-[2-(dimethylamino)prop-1-enyl]-1,3-dimethyluracil (16, 1 mmol), aromatic aldehyde (2, 1 $\mathrm{mmol}), \mathrm{NH}_{4} \mathrm{OAC}$ (3a, $\left.2 \mathrm{mmol}\right), \mathrm{EtOH}(5 \mathrm{~mL})$ reflux, $4 \mathrm{~h}$. b Isolated yield.

Although detailed mechanistic experiments were not performed, the formation of 7-methyl-substituted pyrido[4,3-d]pyrimidine can be mechanistically outlined as in Scheme 3. One possible sequence starts with the formation of aldimine $\mathbf{5}$ between aromatic aldehyde $\mathbf{2}$ and ammonium acetate $3 \mathbf{a}$ and this then undergoes [4+2]-cycloaddition reaction with the diene system of uracil $\mathbf{1 b}$, generating 7-methyl-substituted pyrido[4,3- $d$ ]pyrimidine derivatives 4a-m. . $^{\text {3e }}$ Alternatively, the reaction may proceed via formation of Michael adduct $\mathbf{6}$ from $\mathbf{1 b}$ and $\mathbf{5}$ and this can lead to products $\mathbf{4 a - m}$ by nucleophilic attack on the methyl-substituted carbon atom of the side chain of the pyrimidine ring followed by elimination of the amine moiety and oxidative aromatization. ${ }^{7}$<smiles>[R]c1nc(C)cc2c1c(=O)n(C)c(=O)n2[14CH3]</smiles>

Scheme 2 


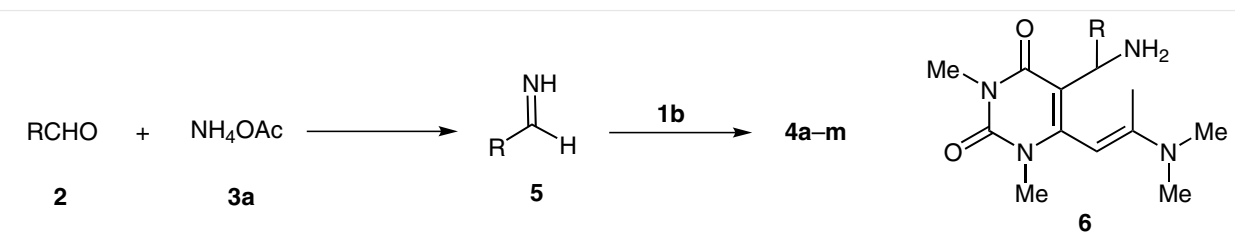

Scheme 3

Although our initial reaction with urea was unsuccessful, we persisted with the concept that urea/thiourea are good sources of ammonia and repeated the model reaction by employing urea/thiourea in place of ammonium acetate under identical reaction conditions. Accordingly, when 6-[2-(dimethylamino)prop-1-enyl]-1,3-dimethyluracil (1 mmol) was ultrasonicated with 4-fluorobenzaldehyde (1 $\mathrm{mmol}$ ) and urea/thiourea ( $2 \mathrm{mmol}$ ) in ethanol, we observed a poor yield of product was after 45 minutes (10\% yield, Scheme 4 , path A). The difference in reactivity of ammonium acetate and urea/thiourea may be attributed towards their different abilities to liberate ammonia and form the aldimine intermediate.

We also carried out the reaction under classical conditions and compared the results with those obtained under ultrasound conditions. Thus, when an ethanolic solution of 6-[2-(dimethylamino)prop-1-enyl]-1,3-dimethyluracil (1 mmol), 4-fluorobenzaldehyde (1 $\mathrm{mmol})$, and ammonium acetate $(2 \mathrm{mmol})$ was refluxed for four hours, product $4 \mathbf{a}$ was obtained with a yield of $75 \%$ (Scheme 4, path B). Further increase in reaction time $(5 \mathrm{~h})$ resulted in decomposition and lower yields. Thus application of ultrasound not only prevents side products but also reduces reaction time. The yields of products under both ultrasound and thermal conditions are shown in Table 1.

In summary, we have developed a convenient multicomponent strategy for the preparation of 7-methyl-substituted pyrido[4,3- $d]$ pyrimidine derivatives. A range of substituted aromatic aldehydes has been shown to undergo an ultrasound-mediated one-pot reaction with vinyluracil and ammonium acetate to generate 7-methyl-substituted pyrido[4,3-d]pyrimidines. This conversion is possible under classical conditions but gives lower yields. We believe that this simple, rapid, and efficient synthesis of 7-methylsubstituted pyrido[4,3-d]pyrimidines is a valuable addition to the chemistry of aza-heterocycles.

\section{Acknowledgment}

We are grateful to CSIR, New Delhi for financial support to this work under network project. We also thank the Director, CSIR-NEIST, Jorhat for his keen interest and constant encouragement.

\section{Supporting Information}

Supporting information for this article is available online at http://dx.doi.org/10.1055/s-0034-1378923.

\section{References and Notes}

(1) Baig, R. B. N.; Varma, R. S. Chem. Soc. Rev. 2012, 41, 1559.

(2) (a) Pizzuti, L.; Franco, M. S. F.; Flores, A. F. C.; Quina, F. H.; Pereira, C. M. P. Recent Advances in the Ultrasound-Assisted Synthesis of Azoles, In Green Chemistry - Environmentally Benign Approaches; Kidwai, M., Ed.; InTech: Rijeka, 2012. (b) Palimkar, S. S.; Kumar, H. P.; Lahoti, J. R.; Srinivasan, V. K. Tetrahedron 2006, 62, 5109. (c) Ambulgekar, V. G.; Bhanage, M. B.; Samant, D. S. Tetrahedron Lett. 2005, 46, 2483. (d) Ross, N. A.; MacGregor, R. R.; Bartsch, R. A. Tetrahedron 2004, 60, 2035. (e) Rajagopal, R.; Jarikote, V. D.; Srinivasan, K. V. Chem. Commun. 2002, 616.

(3) (a) Sarmah, M. M.; Prajapati, D. RSC Adv. 2014, 4, 22955. (b) Sarmah, M. M.; Bhuyan, D.; Prajapati, D. Synlett 2013, 24, 1667. (c) Sarmah, M. M.; Prajapati, D.; Hu, W. Synlett 2013, 24, 471. (d) Sarmah, M. M.; Sarma, R.; Prajapati, D.; Hu, W. Tetrahedron Lett. 2013, 54, 267. (e) Sarma, R.; Sarmah, M. M.; Prajapati, D. J. Org. Chem. 2012, 77, 2018.

(4) Tsupak, E. B.; Tkachenko, Y. N.; Pozharskii, A. F. Chem. Heterocycl. Compd. 1994, 30, 1077.

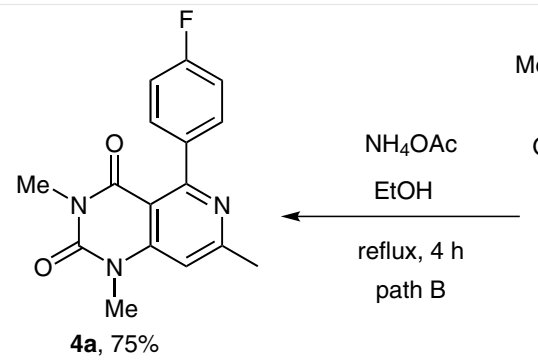

$4 a, 75 \%$

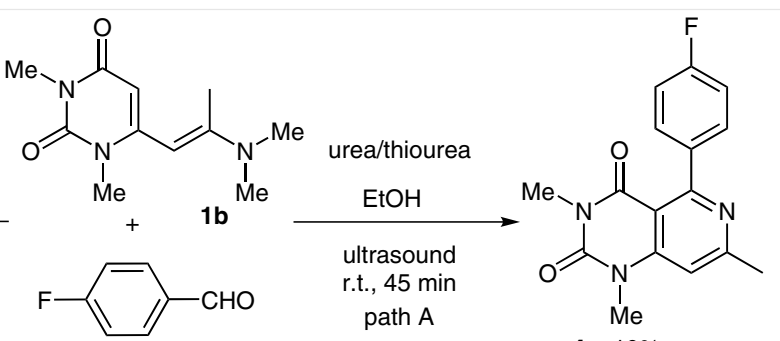

2a

4a, $10 \%$ 
(5) (a) Kostrub, V. V.; Tsupak, E. B.; Smoĺyakov, A. F. Russ. Chem. Bull. Int. Ed. 2009, 58, 1469. (b) Tominaga, Y.; Kohra, S.; Okuda, H.; Ushirogochi, A.; Matsuda, Y.; Kobayashi, G. Chem. Pharm. Bull. 1984, 32, 122. (c) Gavrilenko, I. A.; Kostrub, V. V.; Tsupak, E. B. Russ. Chem. Bull. Int. Ed. 2012, 61, 623. (d) Kostrub, V. V.; Tsupak, E. B. Russ. Chem. Bull. Int. Ed. 2009, 58, 1465. (e) Kostrub, V. V.; Tsupak, E. B.; Tkachenko, Y. N.; Shevchenko, M. A. Russ. Chem. Bull. Int. Ed. 2008, 57, 1754.

(6) Typical Procedure

A mixture of 6-[2-(dimethylamino)prop-1-enyl]-1,3-dimethyluracil (1b; $1 \mathrm{mmol}), 4$-fluorobenzaldehyde (2a; $1 \mathrm{mmol})$, and $\mathrm{NH}_{4} \mathrm{OAc}$ (3a; $2 \mathrm{mmol}$ ) in EtOH ( $5 \mathrm{~mL}$ ) was ultrasonicated for 30 min in a Cole-Parmer 130 watt ultrasonic processor (Model
04714-51) at 70\% amplitude. After reaction, the solvent was removed under reduced pressure, the crude product dissolved in EtOAc and directly purified by column chromatography eluting with 2:1 EtOAc-hexane to obtain pure 5-(4-fluorophenyl)-1,3,7-trimethylpyrido[4,3-d]pyrimidine-2,4-dione (4a) as an off-white solid; $\mathrm{mp} 217-219{ }^{\circ} \mathrm{C} .{ }^{1} \mathrm{H}$ NMR $\left(300 \mathrm{MHz}, \mathrm{CDCl}_{3}\right)$ : $\delta$ = 7.37-7.04 (m, $\left.4 \mathrm{H}, \mathrm{H}_{\text {arom }}\right), 6.92\left(\mathrm{~s}, 1 \mathrm{H}, \mathrm{CH}=\mathrm{CCH}_{3}\right), 3.57(\mathrm{~s}, 3 \mathrm{H}$, $\left.\mathrm{NCH}_{3}\right), 3.30\left(\mathrm{~s}, 3 \mathrm{H}, \mathrm{NCH}_{3}\right), 2.66\left(\mathrm{~s}, 3 \mathrm{H}, \mathrm{CH}_{3}\right) .{ }^{13} \mathrm{C} \mathrm{NMR}(75 \mathrm{MHz}$, $\left.\mathrm{CDCl}_{3}\right): \delta=164.6,162.2,161.6,160.1,150.9,148.0,136.4,130.4$ (2 C), 114.9 (2 C), 106.9, 106.2, 31.1, 28.6, 25.2. MS (GC-MS): $m / z=299[\mathrm{M}]^{+}$. Anal. Calcd for $\mathrm{C}_{16} \mathrm{H}_{14} \mathrm{FN}_{3} \mathrm{O}_{2}: \mathrm{C}, 64.21 ; \mathrm{H}, 4.71 ; \mathrm{N}$, 14.04; O, 10.69. Found: C, 64.20; H, 4.68; N, 14.00; O, 10.61.

(7) Prajapati, D.; Borah, K. J.; Gohain, M. Synlett 2007, 595. 